
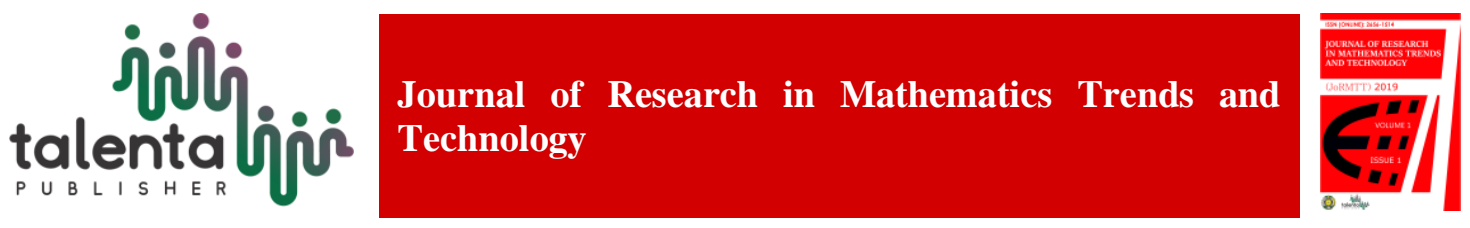

\title{
Depot Location Problems by Considering Its Distribution Problems
}

\section{Henny Sartika ${ }^{1}$ and Mohammad Daniel Hendri Gamal ${ }^{*}$}

${ }^{1}$ Department of Mathematics, University of Riau, Pekanbaru, Indonesia

\begin{abstract}
In this paper we study the problem of locating $m$ depots to serve $n$ customers in order to minimize the total transportation cost. The way the depots serve the customers is considered as a traveling salesperson problem. We combine the location and the traveling salesperson problem methods to find the near-optimal or the best depot locations. An illustrative example is presented to implement the proposed method.
\end{abstract}

Keywords: Heuristic Method, Location Problem, Traveling Salesperson Problem.

\begin{abstract}
Abstrak. Dalam makalah ini kami mempelajari masalah penempatan $m$ depot untuk melayani n pelanggan untuk meminimalkan total biaya transportasi. Cara depot melayani pelanggan dianggap sebagai masalah tenaga penjual keliling. Kami menggabungkan lokasi dan metode masalah tenaga penjual keliling untuk menemukan lokasi depot yang mendekati optimal atau lokasi depot terbaik. Contoh ilustrasi disajikan untuk mengimplementasikan metode yang diusulkan.
\end{abstract}

Kata Kunci: Metode Heuristik, Masalah Lokasi, Masalah Tenaga Penjual Keliling.

Received 13 November 2018 | Revised 15 January 2019| Accepted 22 February 2019

\section{Introduction}

The success or failure of the business of a company or public facilities are strongly influenced by its location. Effective distribution of goods or services will encourage companies to generate profits, reduce production costs, and increase the level of customer satisfaction. Therefore, determining the location of the business or depot is one of the important decisions that must be taken by the business actor.

Proximity in both company and its consumers will certainly help company to maximize its performance and services. Several methods, both exact and heuristic, have been widely discussed by researchers in the past 20 years to obtain optimum locations that minimize the distance from the depots to consumers. The idea of dividing services into $n$ consumers by $m$ depots has been given by Cooper (2001) which was subsequently developed by several researchers using other methods to solve location problems.

\footnotetext{
*Corresponding author at: University of Riau, Pekanbaru, Indonesia

E-mail address: mdhgamal@unri.ac.id
} 
The problem to be studied in this paper is the determination of the depot locations by considering the service given to $n$ consumers by forming the problem of traveling salesman person (TSP) so that the minimum total transportation costs are obtained. Foods or beverages delivery, good repair service, or pickup people or goods service are some examples of these problems. The set of existing consumers will be associated to travelling salesman problem, which each consumer is visited once in a trip starting from the depot and ending by returning to the depot. The problem is probabilistic in that many trips combination formed by $n$ consumers of $m$ depots.

Location problem presented as Steiner-Weber problem. A number of consumers are defined as $n$ fixed points divided into $m$ depot subsets that will be built. Furthermore, the best solution is obtained by determining the route which has minimum transportation cost considering TSP problem.

\subsection{Depot Location Problem}

Mathematical formula to choose the location of $m$ depots of $n$ consumers considers the seller who visits his or her customers using TSP method. Depot location model is formulated as:

$$
\begin{array}{ll}
\operatorname{minimize} & \sum_{i=1}^{m} \sum_{j=1}^{n} x_{i j} d\left(X_{i}, a_{j}\right) \\
\text { subject to } & \sum_{i=1}^{m} w_{i j}=w_{j}, j=1, \mathrm{~K}, n \\
& x_{i j} \geq 0, \text { for all } i \text { and } j
\end{array}
$$

where $x_{i j}$ denote the flow from depot $i$ to consumer $j, X=\left(X_{i}^{1}, X_{i}^{2}\right)$ is the coordinate of depot $i$ location $; i=1,2, \ldots, m, a_{j}=\left(a_{j}^{1}, a_{j}^{2}\right)$ is the coordinate of consumer $j$ location; $j=1,2, \mathrm{~K}, n$, and

$$
d\left(X_{i}, a_{j}\right)=\sqrt{\left(x_{i}-a_{j}\right)^{2}+\left(y_{i}-b_{j}\right)^{2}}
$$

is the Euclidean distance from depot $i$ to customer $j$.

From above model, it show that the objective is to find the minimum total transportation costs formed by optimum distance of depots and consumers. If depots to be built is more than one $(m>1)$, then the objective function neither concave nor convex and and potentially has several local minimum points (Cooper, 1964). The constraint (2) ensures that all consumers can be served, while constraint (3) guarantees that the feasible variable is not negative. This model assumes that the distances of consumers and depots are Euclidean. Beside Euclidean distance, Burness dan White (1976) also use rectilinear distance considering that there might be rivers, mountains, or housing around consumer locations.

Several methods have discussed using iteration algorithm location-allocation by Cooper (1964) to solve multisource Weber problem. Cooper's heuristic method is determining $m$ subset fixed points and then solve each subsets using Weiszfeld exact method (1937) considering each subsets as location-allocation problem for one depot. In addition to Weiszfeld, Kuenne and Soland (1972) formed branch-and-bound algorithm to give exact solution for 25 fixed points. 
Several heuristic methods are introduced to solve larger size location problem. Gamal dan Salhi (2001) built heuristic method based on the farthest distance to find initial location while introducing "restricted areas" to avoid the location of one depot too close to the others. Gamal et al. (2018) also built heuristic method by dividing fixed points into several subset regions using line centered on the rotation point with angle $\alpha$.

\subsection{Weiszfeld Iteration Method}

In this method, basic idea is to divide $n$ fixed point consumers to $m$ subset depots. Best solution will be determined for each subset by solving one depot location problem. Let $k$ denotes the iteration number, then iteration method is defined as:

$$
X^{1(k)}=\frac{\sum_{j=1}^{n} \frac{w_{j} a_{j}^{1}}{d\left(X^{(k-1)}, a_{j}\right)}}{\sum_{j=1}^{n} \frac{w_{j}}{d\left(X^{(k-1)}, a_{j}\right)}} \text { and } \quad X^{2(k)}=\frac{\sum_{j=1}^{n} \frac{w_{j} a_{j}^{2}}{d\left(X^{(k-1)}, a_{j}\right)}}{\sum_{j=1}^{n} \frac{w_{j}}{d\left(X^{(k-1)}, a_{j}\right)}}
$$

Initial point $\left(X^{1^{(0)}}, X^{2^{(0)}}\right)$ needed to obtain $\left(X^{1^{(1)}}, X^{2^{(1)}}\right)$, then $\left(X^{1^{(1)}}, X^{2^{(1)}}\right)$ used to obtain $\left(X^{1^{(2)}}, X^{2^{(2)}}\right)$, etc. The points obtained will converge to the optimal point in the particular subset. When the optimal point obtained, all of consumer fixed points will be allocated to the nearest depot. After all remain points reallocated, then depot location will be improved in the next iteration. This process can be carried out alternately by re-allocating the location to the nearest depot until no modification can be made. After obtaining the optimum location and allocation, the authors determine the optimum travel route using the TSP method in each subset.

\subsection{Traveling Salesman Person Problem}

Given $n$ consumers fixed points so that the distance for each consumer to depot can be found. A route with a minimum distance will be determined so that the seller's route starts from the depot then visits all consumers once and returns to the depot. In other words, there are no sub-tours. The route obtained using TSP will form a circuit known as the Hamiltonian circuit. TSP is known as a classic optimization problem and is categorized as a nondeterministic polynomialtime hard (NP-hard) problem, which there is no optimal solution other than trying all possible solutions, but takes a very long time as the problem increases.

TSP problem can be solved directly or with an approach (heuristics). One of some methods for finding the best solution of TSP problem is calculating all permutations that may be formed from $n$ fixed points consumer and then calculate the minimum costs. However, it is not easy considering that for $n$ fixed points there will be $(n-1)$ ! routes that can be taken. If $n=m+1$, then there are $m$ ! subset routes can be formed so that all consumers can be visited.

TSP problems are widespread among researchers in mathematics, computing, and even management. Several heuristic methods have been developed to solve TSP problem with larger size. Rosenkrantz et al. (1977) built a trip using the closest distance known as nearestneighbour. In addition, genetic algorithm can also be used to solve TSP problem by changing the consumers population into a new gemeration using Darwin evolutionary principles (Khan $e t$ al., 2009). Branch and bound also discussed by a lot of researchers to solve TSP problem. 
In graph theory, TSP problem defined on a graph as $G=(A, D)$, where $A=\left(a_{1}, a_{2}, \ldots, a_{n}\right)$ being a set of $n$ consumer fixed points and $D=\left\{d\left(a_{i}, a_{j}\right) \mid a_{i}, a_{j} \in A, i \neq j\right\}$ being a set of all distance from one point to another point $C=\left(c_{i j}\right)$ is a matrix corresponding to set $A$. TSP problem is symmetric if $c_{i j}=c_{j i}$ for all $\left(a_{i}, a_{j}\right) \in A$ and asymmetric if the opposite.

\subsection{Hungarian Method}

Hungarian Method is a researcher's most often used method for TSP Problem. Following are the steps to solve TSP problems using the Hungarian method:

Step 1: $\quad$ Arrange tables using elements of the matrix $C=\left(c_{i j}\right)$.

Step 2: $\quad$ Subtract the smallest entry in each row from each entry in that row.

Step 3 : $\quad$ Subtract the smallest entry in each row from each entry in that row.

Step 4: Draw horizontal and vertical lines to a minimum number to cover all zeros in the matrix and some elements in the row or column that do not meet the conditions in step 4 are uncovered. In this step you will also get at least one zero in each row and column. If the number of lines are equal to many points, then proceed to step 6. If many lines are smaller than many points, then proceed to step 5.

Step 5: Arrange reduction table by:

Select the smallest element of all elements that are not covered by the lines. Substract all elements that are not covered by the line with the smallest element in point (i) and add the element that is at the intersection of the line with the smallest element in (i).

Step 6: Route can be made by checking all rows and columns that contain zeros. Select the only zero in the corresponding row and column first and then choose another zero that has not been allocated to the route. If the route has not formed a cycle yet, repeat step 5 until the route meets the TSP problem is obtained.

\section{Materials and Methods}

This paper used secondary data from the location of 7 consumers who will be allocated to two depots taken from Cooper's location problem (1963). The assumptions that must be fulfilled in this paper are

a) location of the consumer and depot are euclidean,

b) the minimum cost on TSP is proportional to the minimum distance of the consumer and the depot on the TSP problem,

c) the depot location is not in the same place.

The authors combined Weiszfeld method for location problem and Hungarian method for TSP problem to solve depot location problem by considering its distribution problem. The steps for determining the best solution can be arranged as follows:

Step 1: $\quad$ Select randomly the initial location for $m$ depot. Allocate each consumer's fixed point to the nearest depot.

Step 2: $\quad$ For each set of consumer allocation parts, determine the optimal location using equation (5).

Step 3: $\quad$ Reallocate consumer fixed points to the nearest depot obtained from Step 2.

Step 4: $\quad$ Determine the best TSP route from each subset. 
Step 5: $\quad$ Repeat steps 1 to 4 by $k$ times.

Step 6: The best solution for location problems by considering the distribution using TSP problems is obtained when the total cost of the $m$ depot is minimum.

\section{Results and Discussion}

We illustrate the method by giving an example of solving the depot location problem by considering TSP problem as the distribution of goods or services used. Given seven consumer's location which coordinate $1^{\text {st }}$ consumer $(15,15), 2^{\text {nd }}$ consumer $(5,10), 3^{\text {rd }}$ consumer $(10,27), 4^{\text {th }}$ consumer $(16,8), 5^{\text {th }}$ consumer $(25,14), 6^{\text {th }}$ consumer $(31,23)$, and $7^{\text {th }}$ consumer $(22,29)$ that will be served by two depots. Figure 1 shows depot location and consumers allocation divided into two subsets as first probability. Chosen coordinate depot $1(12,12)$ as initial point that will serve consumer 1, 2, 4, and 5, while initial point for Depot 2 is $(20,30)$ that will serve consumer 3, 6, and 7. By using Weiszfeld iteration method, obtained the best coordinate location for certain subsets is $(15,12)$ for Depot 1 and $(22,29)$ for Depot 2.

Furthermore, TSP solutions are calculated for each subset using the Hungarian method. The distance of each consumer and depot are formed by considering the cost of distribution in proportion to the Euclidean distance as shown in Table 1 and Table 2.

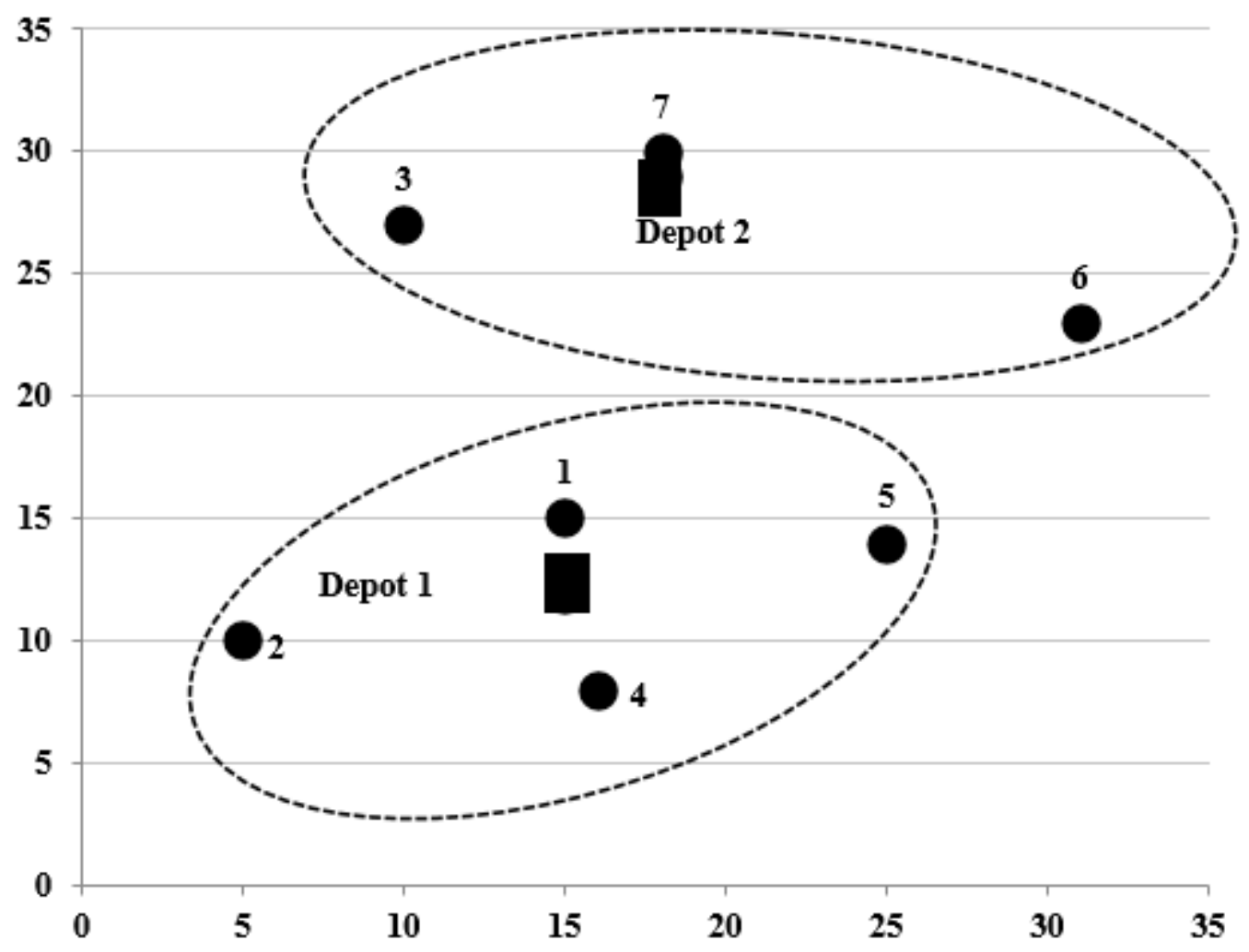

Figure 1 Best solution for $n=7$ and $m=2$ depot on the first subsets 
Table 1 Euclidean distance of consumers and depot on the first subsets

\begin{tabular}{cccccc}
\hline & Depot 1 & 1 & 2 & 4 & 5 \\
\hline Depot 1 & - & 4 & 7 & 6 & 13 \\
1 & 4 & - & 11 & 7 & 10 \\
2 & 7 & 11 & - & 11 & 20 \\
4 & 6 & 7 & 11 & - & 11 \\
5 & 13 & 10 & 20 & 11 & - \\
\hline
\end{tabular}

Table 2 Euclidean distance of consumers and depot on the second subsets

\begin{tabular}{ccccc}
\hline & Depot 2 & 3 & 6 & 7 \\
\hline Depot 2 & - & 10 & 13 & 2 \\
3 & 10 & - & 21 & 9 \\
6 & 13 & 21 & - & 15 \\
7 & 2 & 9 & 15 & - \\
\hline
\end{tabular}

According to Hungarian Method, the best route for the first subsets starts from Depot 1 consumer 1 - consumer 5 - consumer 4 - consumer 2 - Depot 1 which cost 43 units. Furthermore, the best route for the second subsets starts from Depot 2 - consumer 7 - consumer 3 - consumer 6 - Depot 2 which cost 45 units. Thus, the total cost for serving 7 consumers by 2 depots is 88 unit. Figure 2 below shows the best travel routes that can be taken using TSP method.

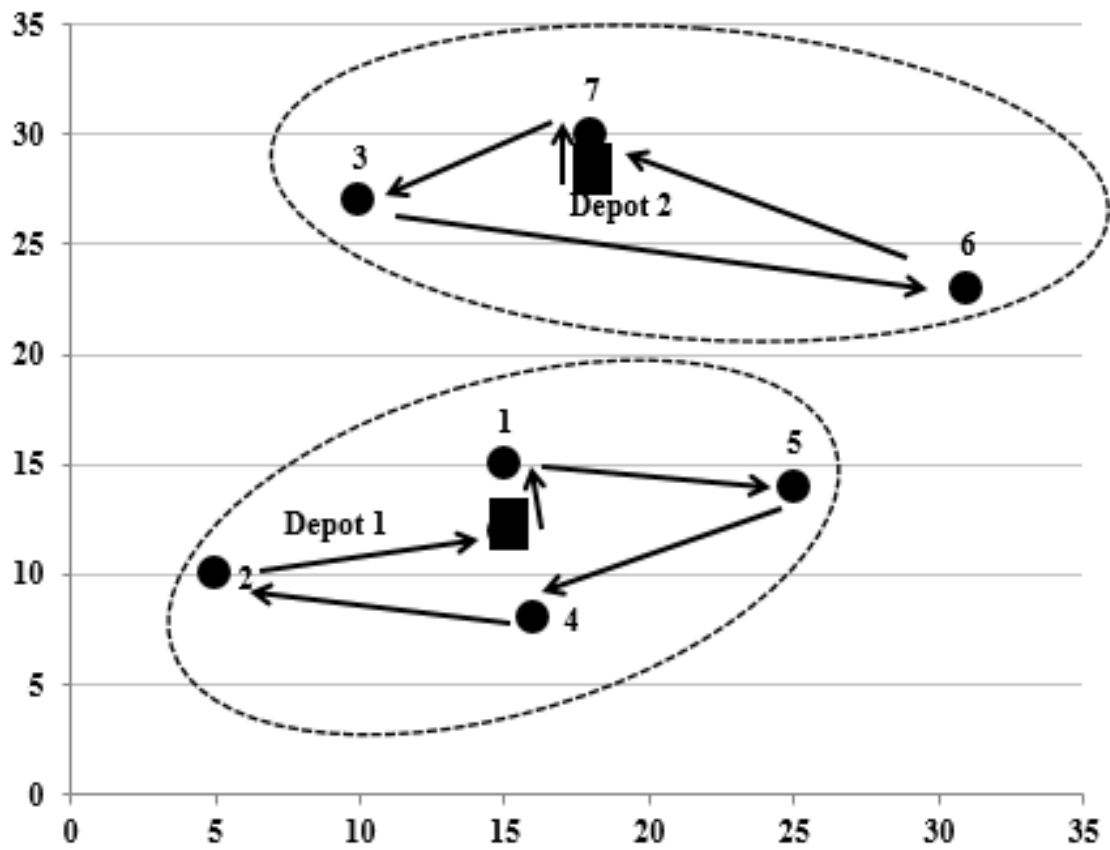

Figure 2 Best route for $n=7$ and $m=2$ depot for the first subset considering its distribution tsp problem

Table 3 shows the calculation results of several possible subsets that can be formed from seven consumers who will be served by two depots. By recording each of the best solutions from each set, it is found that the best solution for the problem of determining location by considering the distribution is to build Depot 1 in $(13,11)$ and Depot 2 at $(20,25)$ with a route for Depot 1 is $D_{1-}$ 1-4-2- $\mathrm{D}_{1}$ and route for Depot 2 is $\mathrm{D}_{2}-7-3-5-6-\mathrm{D}_{2}$ which total cost is 84 units. The best travel routes that can be taken using the TSP method from the location of the depot that has been obtained by collecting the total costs from the possible set of parts that can be formed can be seen in Figure 3. 
Table 3 Location and route data as well as total costs for consumer subsets formed from seven consumers who will be served by two depots

\begin{tabular}{ccccc}
\hline & Depot Location & Consumer's Subsets & Route & Total Cost \\
\hline \multirow{2}{*}{1} & $(12,12)$ & $\{1,2,4,5\}$ & $\mathrm{D}_{1}-1-5-4-2-\mathrm{D}_{1}$ & \multirow{2}{*}{88 units } \\
& $(20,30)$ & $\{3,6,7\}$ & $\mathrm{D}_{2}-7-3-6-\mathrm{D}_{2}$ & \\
2 & $(12,22)$ & $\{1,2,3,7\}$ & $\mathrm{D}_{1}-3-7-1-2-\mathrm{D}_{1}$ & \multirow{2}{*}{98 units } \\
& $(25,14)$ & $\{4,5,6\}$ & $\mathrm{D}_{2}-5-6-4-\mathrm{D}_{2}$ & \\
3 & $(13,11)$ & $\{1,2,4\}$ & $\mathrm{D}_{1}-1-4-2-\mathrm{D}_{1}$ & \multirow{2}{*}{84 units } \\
& $(20,25)$ & $\{3,5,6,7\}$ & $\mathrm{D}_{2}-7-3-5-6-\mathrm{D}_{2}$ & \\
4 & $(14,15)$ & $\{1,2,3,4\}$ & $\mathrm{D}_{1}-1-4-2-3-\mathrm{D}_{1}$ & \multirow{2}{*}{97 units } \\
& $(27,22)$ & $\{5,6,7\}$ & $\mathrm{D}_{2}-6-5-7-\mathrm{D}_{2}$ & \\
5 & $(13,26)$ & $\{1,3,7\}$ & $\mathrm{D}_{1}-3-7-1-\mathrm{D}_{1}$ & \multirow{2}{*}{101 units } \\
& $(23,14)$ & $\{2,4,5,6\}$ & $\mathrm{D}_{2}-5-6-4-2-\mathrm{D}_{2}$ & \\
6 & $(12,16)$ & $\{1,2,3\}$ & $\mathrm{D}_{1}-1-2-3-\mathrm{D}_{1}$ & \multirow{2}{*}{104 units } \\
\hline
\end{tabular}

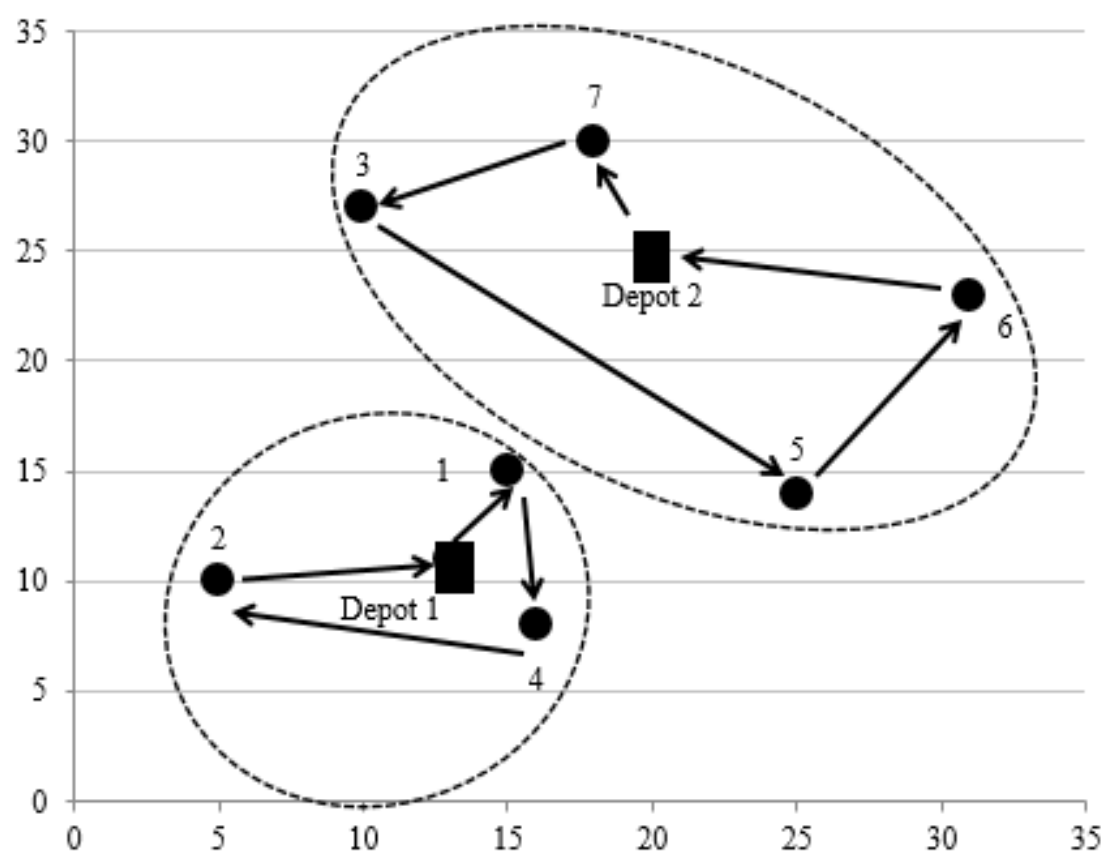

Figure 3 The best location and route solution of $n=7$ consumers and $m=2$ depots by considering the distribution using TSP

\section{Conclusion}

Some things can be concluded from determining the depot location by considering the distribution problem using the TSP method:

(i) The exact and heuristic methods can be used to determine the location of the $m$ depot if the location and cost are known for each fixed point.

(ii) The best solution for determining TSP locations and routes for each depot requires complex calculations. Heuristic approaches and computational calculations are needed to accelerate the optimum solution.

This paper is limited to a combination of Weiszfeld and Hungarian iteration methods. In further development, modifications can be made to the model for determining the location and TSP method. For example, by dividing the area into several regions to avoid the location of a depot too close to other depots. 
Acknowledgements

The author would like to thank the Postgraduate Faculty of Mathematics and Natural Sciences, University of Riau for providing moral support so that this paper can be completed.

\section{REFERENCES}

[1] A. Sapta, "Use of Edmodo In Improving Self-Efficacy", Prosiding Universitas Medan Area, vol. 1 no. 1, 2018.

[2] R. C. Burness and J. A. White, "The Traveling Salesman Location Problem", Journal Transportation Science, vol. 10, no. 4, pp. 348-360, 1976.

[3] L. Cooper, "Heuristic Methods for Location-Allocation Problems", Society of Industrial and Applied Mathematics (SIAM) Review, vol. 6 no. 1, pp. 37-53, 1964

[4] G. B. Dantzig, Linear Programming and Extensions, Princeton University Press, New Jersey, USA, 1963.

[5] S. Eilon, C. D. T. Watson-Gandy and N. Christofides, Distribution Management: Mathematical Modelling and Practical Analysis, Hafner, New York, 1971.

[6] M. D. H. Gamal and S. Salhi, "Constructive Heuristics for the Uncapacitated Continuous Location-Allocation Problems", Journal of the Operation Research Society, vol. 52, pp. 821-829, 2001

[7] M. D. H. Gamal, Zulkarnain and M. Imran, "A Rotary Heuristics for Uncapacitated Continuous Location-Allocation Problems", Accepted in International Journal of Operational Research, 2018.

[8] F. H. Khan, N. Khan, S. Inyatullah and S. T. Nizami, "Solving TSP Problem by Using Genetic Algorithm", International Journal of Basic And Applied Sciences, vol. 9, no. 10, pp. 79-88, 2009.

[9] G. Laporte, "The Travelling Salesman Problem: An Overview of Exact and Approximate Algorithms", European Journal of Operational Research, vol. 59, pp. 231-247, 1992.

[10] D. J. Rosenkrantz, R. E. Streans and M. L. Philip, "An Analysis of Several Heuristics for the Traveling Salesman Problem", SIAM Journal on Computing, vol. 6, pp. 563-581, 1977

[11] E. Wieszfeld, "Sur le Point Pour Lequel la Somme des Distances de $n$ Points Donnés est Minimum”, Tôhoku Mathematical Journal, vol. 43, pp. 355-386, 1937. 